\title{
Effects of Non-Contact Corrective Exercise Continuum for 12 Weeks on Postural Imbalance in Adults
}

\author{
Jin Kim', Jae Ho Khil2,* \\ ' Deparment of Sports Medicine and Science, Graduate School of Physical Education, Kyunghee University, Republic of Korea \\ 2 Department of Sports Medicine, Kyunghee University, Republic of Korea
}

Received: April 30, 2021

Accepted: August 19, 2021

Published online: October 31, 2021

Keywords:

Central Asymmetry

Corrective Exercise Continuum

Forward Head Posture

Postural Imbalance

Video-Based Non-Contact

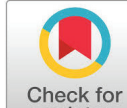

Check for
updates

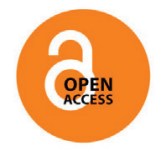

\section{ABSTRACT}

OBJECTIVES This study was to examine the effect of the 12-week video-based non-contact corrective exercise continuum (CEC) program on the forward head posture, central asymmetry, varus and valgus knees for men and women with postural imbalance.

METHODS Subjects were recruited openly by the Internet community and measured their posture with a 3D whole body scanner (Medicube WS-210, Korea), and then classified into exercise group ( $n=32, E G$ ) and control group ( $n=32, C G)$. Total subjects were classified into forward head posture exercise group $(n=8)$, central asymmetry exercise group $(n=8)$, varus exercise group $(n=8)$, valgus exercise group and each control group ( $n=8$ ). For the non-contact home training, 12 weeks of 30 minutes/day, 3 times/week, corrective exercise continuum were conducted. The CEC program is an effective treatment to correct the anatomical alignment of the extremities as suggested by the National Academy of Sports Medicine.

RESULTS As a result, the distance between the centers according to the forward head posture CEC program in $E G$, the angle of spinal inclination of the cervical and thoracic vertebrae, and central asymmetry were lowered $(p<.05)$. Body shape distribution balance and shoulder tilt angle were lowered in EG according to the central asymmetry CEC program $(p<.05)$. According to the varus CEC program in EG, the distance between the center of the knee, the tilt angle of the femur and tibia, and body shape distribution were lowered $(p<.05)$. According to the valgus CEC program in EG, the distance between the center of the knee increased, and the tilt angle of the femur and tibia decreased $(p<.05)$.

CONCLUSIONS The effect of improving the anterior head posture, central asymmetry, varus and valgus knees of postural imbalance according to the CEC program was confirmed. It is thought that the CEC program can restore optimal neuromuscular control by restoring proper joint kinematics and restore posture and balance by reducing the observed muscle tension.

๑ The Asian Society of Kinesiology and the Korean Academy of Kinesiology
서론

현대사회에는 컴퓨터나 책상에 앉아 있는 시간이 길 며, 이는 잘못된 자세 습관으로 이어져 흔히 거북목으 로 일컫는 전방머리자세(forward head posture)를 유 발시킨다[1]. 전방머리자세는 바른 자세와 비교하여 목 에 약 3.6 배의 큰 압력을 주어[2] 장시간 머리의 무게

Correspondence: Jae Ho Khil, Sports Medicine, Kyunghee University, Giheung-gu Deog-yeongdaero 1732, Yongin, Republic of Korea; Tel: +82-10-3938-7644; E-mail: e-mail: jhkhil@khu.ac.kr
를 지탱하면서 목의 자세 변형과 함께 통증이 발생한다 [3]. 이러한 문제점을 해결하기 위한 방법으로 전방머 리자세 개선을 위해 자세교정 장치를 활용하며, 운동화 와 자세교정 벨트 등 다양한 도구를 이용한 자세교정운 동, 필라테스와 코어 운동과 같은 여러가지 운동이 활 용되고 있다 [4, 5].

장기간의 잘못된 자세습관으로 인한 근육 불균형은 근골격계의 비대칭 및 기능 저하를 가져오고[6], 중심 비대칭의 잘못된 정렬로 인하여 어깨와 등 부위의 등세 
모근과 어깨뼈 근육이 단축되며 목 굴곡근과 중부 및 하 부등세모근의 비대칭을 동반한다. 이러한 비대칭은 등세 모근과 같은 근육의 약화로 어깨뼈 외전을 증가시킨다. 교정 운동은 골격근을 활성화하여 신체 부위를 정상 범 위 수준의 정렬 상태로 만들어 자세와 기능을 개선하는 데 활용되어 왔으며, 선행연구에서는 후부 어깨와 목뼈 근육을 강화하면 수영선수의 목뼈와 등뼈의 각도와 어 깨 각도가 감소한다고 보고했다 $[7,8]$.

무릎 관절은 동적 및 정적 활동과 같은 신체활동 시 신체를 지지하고 체중을 분산하여 전달 하는데 중요한 역할을 한다. 무릎 기형 중 하나인 외반슬과 내반슬은 신 체의 지지대에 대한 무게 중심의 이동과 분산을 방해하 여 궁극적으로 균형에 좋지 않은 영향을 미친다[9]. 이 와 같은 무릎 기형은 무릎 관절의 기계적 축 편차에 영 향을 미치고, 이와 관련하여 무를 기형 교정 운동은 무 릎 기형을 교정할 수 있다[10].

흥미롭게도 교정 운동이 자세 교정에 광범위하게 활 용되고 있음에도 불구하고 그 효과를 뒷받침하는 과학적 데이터가 있으나 어떤 교정 운동이 가장 효과적인 교정 운동 인지에 대해서는 검증된 바가 거의 없다[11]. 따 라서 자세 이상이 있는 개인의 회복과 예방을 위한 실행 가능하고 효과적인 교정 운동에 대한 연구가 필요하다.

교정 운동은 정상범위를 벗어난 척추 만곡을 정상 범위로 교정하는 일반적인 방법 중 하나이다. 정상범 위의 요추 상태를 유지하려면 교정 운동을 통하여 불 안정하고 약해진 근육을 강화해야한다[12]. 다양한 교정 운동 방법 중 운동 연속체(corrective exercise continuum: CEC) 프로그램은 미국스포츠의학협회 (National Academy of Sports Medicine: NASM)에 서 제시한 프로그램으로 구성되어 사지의 해부학적 정 렬을 수정하는 효과적인 운동 방법이다[13]. CEC는 총 4 단계로 구성되어 있으며, 1 단계에서는 과민성 근육 과 근막 억제를 위한 자가근막이완법(self-myofascial release: SMR)을 사용하고[14], 2단계에서는 과사용 된 근육에 대한 스트레칭을 실시한다. 3단계에서는 비 활성화 된 근육 강화를 위한 근력운동으로 자세적 등척 성(positional isometrics) 운동방법이 사용되어 근력강 화를 유도한다. 자세적 등척성 운동은 관절의 가동범위 끝 범위에서 등척성 수축을 하여 근육들의 기능적 협력 을 위한 협응능력을 증가시킨다. 마지막으로 4단계에서 는 점진적 움직임을 통합하여 전신 근육의 집단적 시너
지 기능을 재훈련 한다.

대부분의 교정 운동은 일반적으로 개인의 근본적 인 근육 불균형을 개선 시키지만, 기능적 운동과 관련 한 근육 불균형의 원인 및 치료에 대해 두 가지 접근 방식은 차이가 있다. 그것은 생체 접근법과[15] 신경 근 접근법[16]이다. 생체 접근법은 생역학적 패러다임 (biomechanical paradigm)으로 전통적인 근육불균형 이론이며 지속적인 잘못된 자세와 움직임으로 스트레 스가 누적되어 근육불균형이 발생되는 이론이다[15]. 신경근 접근법은 신경학적 패러다임(neurological paradigm)으로 신경근계의 조절부전이 중추신경계에 잘못된 출력 신호를 송출하여 근육불균형을 유발할 수 있다는 이론이다[16]. 두 방법 모두 근육 조직구조와 적 응, 신경 메커니즘 및 생체 역학 원리를 포함하여 근육 불균형을 신경근 불균형으로 설명한다. 본 연구에서 적 용한 $\mathrm{CEC}$ 는 신경근 불균형의 두 가지 방법 모두 중재 요소를 통합하여 연구의 의미를 두었다.

또한, $\mathrm{CEC}$ 의 실시와 함께 중재 후 신체 활동을 증 가시키기 위한 행동 변화 전략을 구성하여 신체 활동량 을 늘리고, 건강한 생활습관을 유지하는데 효과적인 피 드백을 제공하였다[17]. 대상자의 현재 상태에 대하여 측정하고 분석하여 피드백을 제공하고, 자세불균형 환 자의 신체활동 기반에 대한 순응도를 높인다[18]. 제공 되는 피드백에는 자가 모니터링, 목표 설정, 행동 계획 과 함께 대면 또는 비대면 방법을 통하여 제공한다. 디 지털 기술을 통한 비대면 교육 및 학습의 장점은 대상 자가 활동 목표를 설정하고 진행상황을 스스로 모니터 링 할 수 있다.

동영상 기반 학습(video-based learning: VBL)은 그림, 텍스트, 소리와 같은 시청각 정보를 결합하여 스 스로 학습하는 방법이다[19]. 우리나라는 정보통신기 술의 발달로 e-Learning 등의 디지털 기반 학습의 발 달과 함께 대중화되어 스마트폰과 같은 모바일 기기를 활용하여 학습자가 원하는 장소와 시간에 학습할 수 있 다. 이와 함께, 비대면 동영상 기반 콘텐츠는 학습자가 반복 시청이 가능하여 개인의 속도와 수준을 조절할 수 있어 학습내용의 이해도를 높일 수 있으나, 자세 교정 과 같이 지도자의 세심한 지도가 필요한 교정운동이 자 세불균형 을 가진 사람의 자세교정을 위한 방법으로 효 과적인지 여부는 검토되지 않았다.

따라서, 본 연구의 목적은 12 주간의 비대면 동영상 
기반 홈트레이닝 $\mathrm{CEC}$ 프로그램 실시가 자세불균형 성 인의 전방머리자세, 중심비대칭, 내반슬 및 외반슬에 미 치는 영향을 비교하는 것이다.

\section{연구방법}

본 연구의 대상자는 $\mathrm{S}$ 시 $\mathrm{K}$ 도에 거주하고, 소셜네트 워크, 인터넷 커뮤니티를 통하여 자세가 불균형하다고 느끼거나 교정을 원하는 성인을 3 차에 걸쳐 모집하였다. 모집된 대상자 중 12 주간의 비대면 동영상 기반 홈트레 이닝 기간을 감안한 탈락률을 고려하여 총 80명을 대상 자로 선정하였으며, 선정된 대상자는 $3 \mathrm{D}$ 매디큐브 체 형분석기(3D whole body scanner-Model; Medicube, $\mathrm{WS}-210)$ 를 이용하여 자세를 측정한 후 전방머리자세, 중심비대칭, 내반슬, 외반슬에서 정상범위에서 많이 벗 어난 항목에 맞춰 집단을 배정하였다. 이중 정상 자세 로 판명된 5명과 연구기간 중 비대면 동영상 기반 홈프 레이닝 프로그램을 유지하지 못한 11명을 제외한 최종
64 명의 측정값을 결과분석에 사용하였다.

자세불균형 판정기준으로 전방머리자세는 귀중심선 이 정상 선에서 $1 \mathrm{~cm}$ 이상, 중심비대칭은 좌·우 체중분 배 차이가 체중 대비 $5 \%$ 이상 [20], 내반슬은 양측발목 에서 복사뼈를 서로 맞닿게 한 후 좌·우 무를 간의 거리 가 $2.5 \mathrm{~cm}$ 이상, 외반슬은 무릎을 서로 닿게 한 후 좌.우 발목의 양복사뼈 간 거리가 $2.5 \mathrm{~cm}$ 이상이다[21]. 대상 자 제외기준은 중증 심혈관계질환, 고도 비만자, 당뇨병 등 신체활동을 제한하는 질환자는 제외하였으며, 선정 된 모든 대상자에게 사전 동의서(Informed consent)를 받았다. 또한 모든 대상자에게 본 연구의 측정 절차, 개 인 이익 및 위험과 관련된 모든 사항을 설명하여 이해 시킨 후 질문에 답변하도록 하였다.

최종 선정된 대상자는 실험군 32 명, 통제군 32 명으 로 구분하였다. 총 선정된 64 명 대상자는 전방머리자세 실험군 8명, 전방머리자세 통제군 8명으로 분류하였고, 중심비대칭 실험군 8 명, 중심비대칭 통제군 8 명, 그리 고 내반슬 실험군 8 명과 중심비대칭 통제군 8 명, 외반

Table 1. Physical characteristics of subjects.

\begin{tabular}{|c|c|c|c|c|}
\hline & Variables & Exercise group $(n=32)$ & Control group $(n=32)$ & $P$ \\
\hline \multirow{5}{*}{$\begin{array}{l}\text { Forward head } \\
\text { posture }\end{array}$} & Age (yrs) & $42.2 \pm 9.8$ & $31.5 \pm 6.5$ & $.022^{*}$ \\
\hline & Weight (kg) & $59.0 \pm 9.7$ & $64.8 \pm 15.7$ & .386 \\
\hline & Height $(\mathrm{cm})$ & $164.3 \pm 9.1$ & $173.0 \pm 10.7$ & .107 \\
\hline & Distance $(\mathrm{cm})$ & $5.1 \pm 1.1$ & $4.3 \pm 1.7$ & .773 \\
\hline & Angle $\left({ }^{\circ}\right)$ & $9.7 \pm 3.5$ & $10.0 \pm 6.1$ & .914 \\
\hline \multirow{5}{*}{ Central asymmetry } & Age (yrs) & $43.2 \pm 11.0$ & $37.8 \pm 8.9$ & .303 \\
\hline & Weight (kg) & $64.2 \pm 11.6$ & $67.0 \pm 7.7$ & .587 \\
\hline & Height $(\mathrm{cm})$ & $166.5 \pm 7.1$ & $173.3 \pm 7.1$ & .076 \\
\hline & Body type distribution balance (kg) & $6.4 \pm 2.5$ & $6.6 \pm 2.6$ & .875 \\
\hline & Angle $\left({ }^{\circ}\right)$ & $3.0 \pm 1.2$ & $3.1 \pm 1.3$ & .940 \\
\hline \multirow{5}{*}{ Genu varus } & Age (yrs) & $39.7 \pm 11.6$ & $34.8 \pm 7.6$ & .340 \\
\hline & Weight (kg) & $72.8 \pm 15.6$ & $70.3 \pm 11.7$ & .723 \\
\hline & Height $(\mathrm{cm})$ & $172.8 \pm 7.7$ & $175.2 \pm 4.8$ & .474 \\
\hline & Distance $(\mathrm{cm})$ & $11.9 \pm 0.6$ & $11.9 \pm 0.7$ & .945 \\
\hline & Angle $\left({ }^{\circ}\right)$ & $4.9 \pm 0.9$ & $5.0 \pm 0.9$ & .781 \\
\hline \multirow{5}{*}{ Genu valgus } & Age (yrs) & $27.0 \pm 4.2$ & $28.0 \pm 5.1$ & .678 \\
\hline & Weight (kg) & $80.1 \pm 12.7$ & $68.5 \pm 17.2$ & .147 \\
\hline & Height (cm) & $176.0 \pm 7.4$ & $168.8 \pm 8.5$ & .097 \\
\hline & Distance (cm) & $4.5 \pm 0.6$ & $4.4 \pm 0.6$ & .773 \\
\hline & Angle $\left({ }^{\circ}\right)$ & $5.6 \pm 1.2$ & $5.6 \pm$ & .993 \\
\hline
\end{tabular}

Values are $M \pm S D, " p<.05$ 
슬 실험군 8과과 외반슬 통제군 8명으로 분류하여 총 4 개의 $\mathrm{CEC}$ 프로그램 집단과 총 4 개의 통제집단으로 분 류하였다. 대상자의 신체적 특성은 <Table 1 >과 같다.

\section{측정도구 및 방법}

\section{1) 전방 머리자세}

전방 머리자세는 $3 \mathrm{D}$ 매디큐브 체형분석기를 이용 하여 측정하였다. 시상면상 전방머리 중심간거리의 판 정 기준은 정상범위의 자세정렬 기준과 일치할 때 5점, 약간 벗어났을 때 3 점, 뚜렷이 벗어났을 때 1점으로 분 류하였다. 두부 전방전위는 목말뼈, 위팔뼈, 귀의 바깥 귀길이 중력선 기준 일직선상에 위치할 때 정상으로 판 정하였고, 귀의 바깥귀길 중심선과 정상선인 0.5 1.0 $\mathrm{cm}$ 벗어난 경우에 경도 변형으로 분류하고, $1 \mathrm{~cm}$ 이상 벗어날 때 고도변형으로 판단하였다. 목뼈의 기울기는 선행연구를 기준으로 측면자세 중 발목 위부터 어깨까 지 척추, 등뼈상부, 목뼈의 두개척추각(craniovertebral angle: CVA)기준을 참고하여 등뼈상부 전방기울기에 준하는 목뼈의 기울기를 측정하였다[22].

\section{2) 중심비대칭}

중심비대칭 측정은 $3 \mathrm{D}$ 매디큐브 체형분석기를 이용 하여 측정하였다. 자세측정 시 $3 \mathrm{D}$ 매디큐브 체형분석 기에서 약 10 초간 좌•우 정적평형성 $(\mathrm{kg})$ 을 측정하였다 [23]. 중심비대칭 판단을 위한 신체균형은 정적 자세에 서 신체의 좌•우가 50:50의 체중 분산을 \%로 환산하여 $5 \%$ 이내가 정상범위 기준으로 적용하였다. 본 연구에 서는 상대적 체중 대비 체중의 $5 \%$ 이상 차이가 날 때 중 심비대칭으로 적용하였다[24]. 어깨기울기는 어깨의 상-하 기울임은 한쪽 어깨돌기를 축으로 다른 어깨돌기 에서 수평 상태이면 정상, 선이 수평에서 벗어나 기울기 가 $3^{\circ}$ 미만일 때 경도 변형, 기울기가 $3^{\circ}$ 이상이면 고 도변형으로 적용하였다[20]. 본 연구에서는 어깨뼈 끝 지점에서 시작하여 목선까지 5 등분한 평균값을 어깨 높 이를 측정기준으로 적용하였다. 어깨 부피는 양어깨돌 기의 높은 점과 끝점을 $3 \mathrm{D}$ 로 측정하였으며, 어깨의 부 피 측정 시 설정한 양어깨돌기의 높은 점을 잇는 가상 선과 지평면과 이루는 수평선 간의 각도차를 통해 이를 어깨 경사로 하였다[23].

\section{3) 내반슬}

내반슬의 측정은 $3 \mathrm{D}$ 매디큐브 체형분석기를 이용하
여 측정하였다. 내반슬은 전면 상태에서 양 무릎 사이 의 거리와 양 넙다리뼈와 정강이뼈의 경사도를 측정기 준으로 하였다. 내반슬은 양측 발목 내측정강이뼈를 서 로 닿게 한 후 무를 중심 거리를 기준으로 사용하였으 며, 양측발목의 정강이뼈 내과를 서로 닿게 한 후 측정 한 양 무릎간의 거리를 측정하였다. 넙다리뼈와 정강이 뼈의 기울기는 넙다리뼈와 정강이뼈의 기울기는 해부 학적 축의 기준으로 넙다리뼈와 정강이뼈의 축이 $180^{\circ}$ 이상으로 평가하였다[21].

\section{4) 외반슬}

외반슬의 측정은 $3 \mathrm{D}$ 매디큐브 체형분석기를 이용하 여 측정하였다. 외반슬은 전면 상태에서 양 무를 간 거 리와 양 넙다리뼈와 정강이뼈의 경사도를 측정기준으로 하였다. 무릎 중심간거리는 양 무릎을 붙인 상태에서 복 사뼈 내측의 간격을 측정하였다[25]. 외반슬은 넙다리 뼈와 정강이뼈 각도를 측정 비교했을 때, 무릎관절과 무 릎이 내측으로 활 모양으로 휜 모양을 말한다. 넙다리뼈 와 정강이뼈의 기울기 해부학적 넙다리뼈의 축과 정강 이뼈의 축이 만나는 각도수치가 $180^{\circ}$ 보다 낮을 때를 기준으로 측정하였다[21].

\section{5) 교정 운동 연속체(CEC) 프로그램}

(1) $\mathrm{CEC}$ 프로그램 과정 및 방법

대상자는 본 연구에서 실시하는 $\mathrm{CEC}$ 프로그램 참여 를 위해 유튜브에 비공개 업로드 된 $\mathrm{CEC}$ 프로그램 영상 과 설명 영상 두 가지의 링크에 접속하여 비대면 동영 상 기반 $\mathrm{CEC}$ 프로그램에 참여하였다. 인터넷커뮤니티 에 가입 후, 본인의 핸드폰 등을 이용해 실제 $\mathrm{CEC}$ 프로 그램을 수행하는 자신의 모습을 동영상으로 촬영한 후 개설된 자신 개인의 게시판에 동영상을 업로드하였으 며, $\mathrm{CEC}$ 프로그램 수행에 대한 궁금증과 어려움에 대하 여 소통 하였다.

운동지도자는 대상자가 주 3 회 $\mathrm{CEC}$ 프로그램에 참여 할 수 있도록 하였으며, 대상자가 업로드한 영상을 확인 하여 개개인의 운동 수행 진행을 확인하였다. 예상하지 못한 동영상촬영의 문제 발생과 동영상 업로드 오류 등 의 문제로 업로드를 하지 못하였을 경우 대상자가 $\mathrm{CEC}$ 프로그램을 참여한 회차별 체크리스트를 작성하여 추가 로 제출하도록 하였다. $\mathrm{CEC}$ 프로그램 참여를 위하여 대 상자 개인의 자세불균형에 따른 운동소도구를 준비할 수 있도록 폼롤러(form roll), 세라케인(thera cane), 짐볼 
(gymball), 트레이닝용밴드(training rubber band), 덤 벨(dumbbell), 메디신볼(medball: option) 구매링크를 안내하였다. 대상자는 TV, 컴퓨터나 노트북, 테블릿 pc 나 핸드폰으로 비대면 동영상 기반 홈트레이닝을 동영 상과 같은 시간으로 진행하였다. 실험군의 $\mathrm{CEC}$ 프로그 램이 실행되는 기간 동안 통제군은 $\mathrm{CEC}$ 프로그램을 제 한하고, 일상생활을 유지하도록 지시하였다.

(2) $\mathrm{CEC}$ 프로그램의 내용

본 연구에서 사용된 $\mathrm{CEC}$ 프로그램은 선행논문에서
의 프로그램 프로토콜을 활용하였다[26]. 대상자는 12 주간, 주 3회, 30분씩, $\mathrm{CEC}$ 트레이닝에 참여하였다. $\mathrm{CEC}$ 는 신경근 불균형의 중재 요소를 통합한 영향을 검 토하는 것에 의미를 두었다. 대상자의 신경근 제어를 복원하고, 신경근 불균형을 수정하기 위해 근본적인 신 경근 결핍을 해결하여 결과적으로 기능적 운동의 질을 향상시키는 프로그램이다. CEC프로그램의 구성은 반 복 횟수와 강도를 통해 생리학적 과부하를 자극하기 위 하여 구성하였으며, <Table 2-5>와 같이 진행되었다.

Table 2. Forward head posture CEC program.

\begin{tabular}{|c|c|c|c|c|c|c|}
\hline & Exercise & Sets & Duration & \multicolumn{3}{|l|}{ Notes } \\
\hline \multirow{4}{*}{$\begin{array}{l}1 \text { Grade } \\
\text { Inhibit }\end{array}$} & Thoracic spine & 1 & $30 \mathrm{sec}$ & \multicolumn{3}{|c|}{ Foam roll or thera cane } \\
\hline & Sternocleidomstoid muscle & 1 & $30 \mathrm{sec}$ & \multicolumn{3}{|c|}{ Finger pressure } \\
\hline & Levator scapula & 1 & $30 \mathrm{sec}$ & \multicolumn{3}{|c|}{ Thera cane } \\
\hline & Upper trapezius & 1 & $30 \mathrm{sec}$ & \multicolumn{3}{|c|}{ Thera cane } \\
\hline \multirow{3}{*}{$\begin{array}{l}2 \text { Grade } \\
\text { Lengthen }\end{array}$} & Sternocleidomstoid muscle & 1 & $30 \mathrm{sec}$ & \multirow{3}{*}{\multicolumn{2}{|c|}{ Static stretching }} & \\
\hline & Levator scapula & 1 & $30 \mathrm{sec}$ & & & \\
\hline & Upper trapezius & 1 & $30 \mathrm{sec}$ & & & \\
\hline \multirow{4}{*}{$\begin{array}{l}3 \text { Grade } \\
\text { Activation }\end{array}$} & Exercise & Sets & Reps & Tempo & Rest & Notes \\
\hline & Quadruped ball chin tucks & $1 \sim 2$ & $10 \sim 15$ & $4 / 2 / 2$ & 0 & Deep neck flexor \\
\hline & $\begin{array}{l}\text { Resisted cervical posterior translation } \\
\text { (Chin Tucks) }\end{array}$ & $1 \sim 2$ & $10 \sim 15$ & $4 / 2 / 2$ & 0 & $\begin{array}{l}\text { Cervical /Thoracic } \\
\text { extensors }\end{array}$ \\
\hline & Floor prone scaption & $1 \sim 2$ & $10 \sim 15$ & $4 / 2 / 2$ & 0 & Lower trapezius \\
\hline $\begin{array}{l}4 \text { Grade } \\
\text { Integrated }\end{array}$ & Ball combo I with cervical retraction & $1 \sim 2$ & $10 \sim 15$ & slow & $30 \mathrm{sec}$ & Ball combo \\
\hline
\end{tabular}

Table 3. Central asymmetry CEC program

\begin{tabular}{|c|c|c|c|c|c|c|}
\hline & Exercise & Sets & Duration & \multicolumn{3}{|l|}{ Notes } \\
\hline \multirow{4}{*}{$\begin{array}{l}1 \text { Grade } \\
\text { Inhibit }\end{array}$} & Adductor & 1 & $30 \mathrm{sec}$ & \multicolumn{3}{|c|}{ Sam side of shift } \\
\hline & Gastrocnemius/Soleus muscle & 1 & $30 \mathrm{sec}$ & \multicolumn{3}{|c|}{ Opposite side of shift } \\
\hline & Piriformis & 1 & $30 \mathrm{sec}$ & \multicolumn{3}{|c|}{ Opposite side of shift } \\
\hline & Biceps femoris & 1 & $30 \mathrm{sec}$ & \multicolumn{3}{|c|}{ Opposite side of shift } \\
\hline \multirow{3}{*}{$\begin{array}{l}2 \text { Grade } \\
\text { Lengthen }\end{array}$} & Adductor & 1 & $30 \mathrm{sec}$ & \multicolumn{3}{|c|}{ Sam side of shift } \\
\hline & Piriformis & 1 & $30 \mathrm{sec}$ & \multicolumn{3}{|c|}{ Opposite side of shift } \\
\hline & Biceps femoris & 1 & $30 \mathrm{sec}$ & \multicolumn{3}{|c|}{ Opposite side of shift } \\
\hline \multirow{3}{*}{$\begin{array}{l}3 \text { Grade } \\
\text { Activation }\end{array}$} & Exercise & Sets & Reps & Tempo & Rest & Notes \\
\hline & $\begin{array}{l}\text { Resisted hip abduction } \\
\text { (same side of shift) }\end{array}$ & $1 \sim 2$ & $10 \sim 15$ & $4 / 2 / 2$ & 0 & $\begin{array}{l}\text { Same side gluteus } \\
\text { Medius }\end{array}$ \\
\hline & $\begin{array}{l}\text { Resisted hip adduction and internal } \\
\text { rotation(opposite side of shift) }\end{array}$ & $1 \sim 2$ & $10 \sim 15$ & $4 / 2 / 2$ & 0 & $\begin{array}{l}\text { Opposite side } \\
\text { adductor }\end{array}$ \\
\hline $\begin{array}{l}4 \text { Grade } \\
\text { Integrated }\end{array}$ & Ball wall squat with overhead press & $1 \sim 2$ & $10 \sim 15$ & slow & $30 \mathrm{sec}$ & $\begin{array}{l}\text { Whole body } \\
\text { intergration }\end{array}$ \\
\hline
\end{tabular}


Table 4. Varus CEC program.

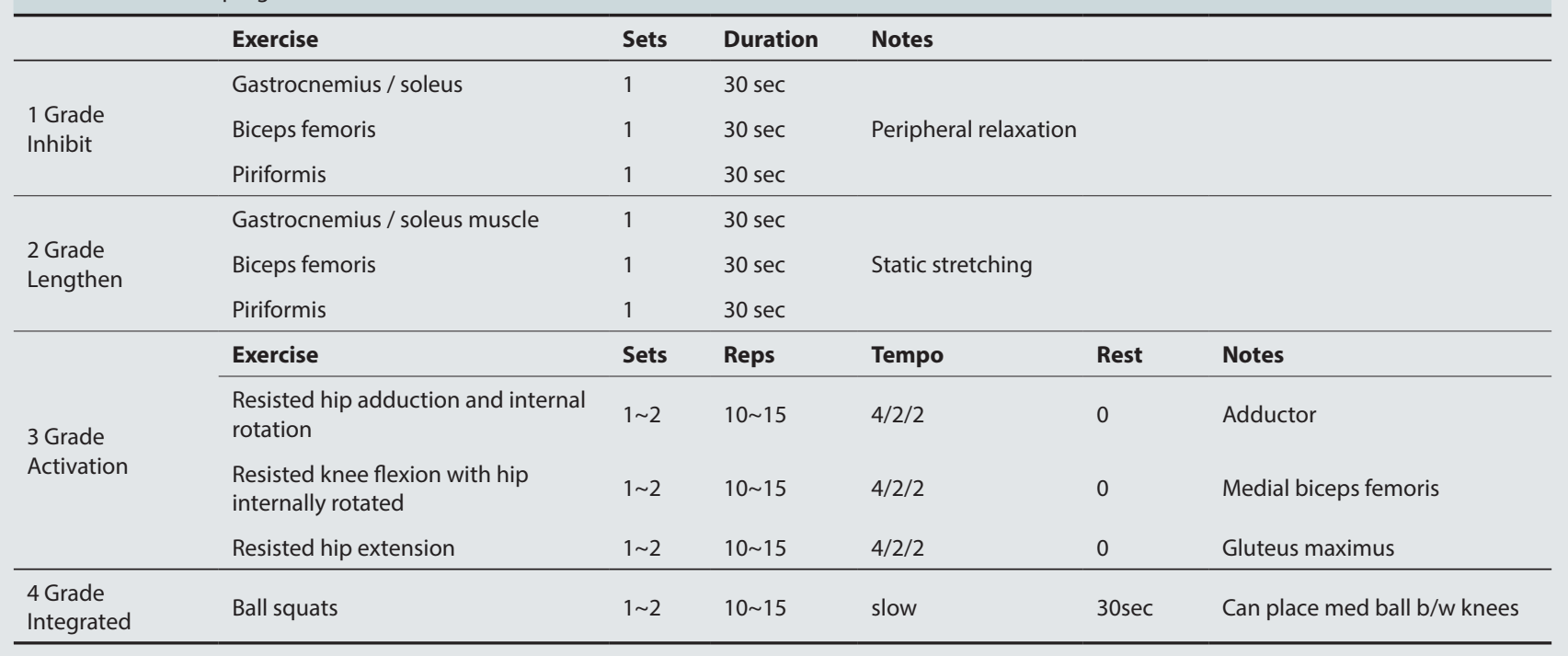

Table 5. Valgus CEC program.

\begin{tabular}{|c|c|c|c|c|c|c|}
\hline & Exercise & Sets & Duration & \multicolumn{3}{|l|}{ Notes } \\
\hline \multirow{4}{*}{$\begin{array}{l}1 \text { Grade } \\
\text { Inhibit }\end{array}$} & $\begin{array}{l}\text { Gastrocnemius/ } \\
\text { Soleus muscle }\end{array}$ & 1 & $30 \mathrm{sec}$ & \multirow{4}{*}{\multicolumn{2}{|c|}{ Peripheral relaxation }} & \\
\hline & Biceps femoris & 1 & $30 \mathrm{sec}$ & & & \\
\hline & Adductor & 1 & $30 \mathrm{sec}$ & & & \\
\hline & Tensor fasciae latae & 1 & $30 \mathrm{sec}$ & & & \\
\hline \multirow{4}{*}{$\begin{array}{l}2 \text { Grade } \\
\text { Lengthen }\end{array}$} & Gastrocnemius/Soleus muscle & 1 & $30 \mathrm{sec}$ & \multirow{4}{*}{\multicolumn{2}{|c|}{ Static stretching }} & \\
\hline & Biceps femoris & 1 & $30 \mathrm{sec}$ & & & \\
\hline & Adductor & 1 & $30 \mathrm{sec}$ & & & \\
\hline & Tensor fasciae latae & 1 & $30 \mathrm{sec}$ & & & \\
\hline \multirow{4}{*}{$\begin{array}{l}3 \text { Grade } \\
\text { Activation }\end{array}$} & Exercise & Sets & Reps & Tempo & Rest & Notes \\
\hline & Resisted ankle dorsiflexion & $1 \sim 2$ & $10 \sim 15$ & $4 / 2 / 2$ & 0 & $\begin{array}{l}\text { Tibialis } \\
\text { anterior muscle }\end{array}$ \\
\hline & $\begin{array}{l}\text { Resisted hip } \\
\text { abducion }\end{array}$ & $1 \sim 2$ & $10 \sim 15$ & $4 / 2 / 2$ & 0 & Gluteus medius \\
\hline & Resisted hip extention & $1 \sim 2$ & $10 \sim 15$ & $4 / 2 / 2$ & 0 & Gluteus maximus \\
\hline $\begin{array}{l}4 \text { Grade } \\
\text { Integrated }\end{array}$ & Wall jumps & $1 \sim 2$ & $10 \sim 15$ & Controlled & $30 \mathrm{sec}$ & \\
\hline
\end{tabular}

\section{자료처리}

수집된 모든 자료는 SPSS Version 25.0 프로그램 을 이용하여 각 변인의 평균과 표준편차를 산출하였고, 시기와 집단 간 종속변인 차이를 분석하기 위하여 반복 이원변량분석(two-way repeated ANOVA)을 실시하 였다. 분석결과 상호작용이 나타난 경우 대응표본 $\mathrm{t}$-검 정(paired t-test)를 실시하였으며, 모든 통계적 유의수 준은 $\alpha=.05$ 로 하였다.

\section{결과}

12 주간의 비대면 동영상 기반 홈트레이닝 CEC프로 그램 실시에 따른 전방머리자세의 변화는 <Table 6>에 제시된 바와 같다. 전방머리자세의 중심간거리 및 목뼈 의 기울기에서 실시 전•후 집단과 시기 간 상호작용이 나타났다 $(\mathrm{p}<.05)$. 전방머리 중심간거리는 $\mathrm{CEC}$ 프로그 램 실험군 $5.1 \pm 1.1 \mathrm{~cm}$ 에서 $2.1 \pm 1.8 \mathrm{~cm}$ 로 통계적으로 
Table 6. Forward head posture changes with CEC program.

\begin{tabular}{|c|c|c|c|c|c|}
\hline & Group & Pre & Post & & $P$ \\
\hline \multirow{3}{*}{$\begin{array}{l}\text { Center-to-center } \\
\text { distance } \\
(\mathrm{cm})\end{array}$} & \multirow{2}{*}{$E G(n=8)$} & $5.1 \pm 1.1$ & $2.1 \pm 1.8^{\#}$ & Time & $.000^{* * *}$ \\
\hline & & & & Group & $.047^{*}$ \\
\hline & $C G(n=8)$ & $5.3 \pm 1.7$ & $5.3 \pm 1.7$ & Time x Group & $.000^{* * *+}$ \\
\hline \multirow{3}{*}{$\begin{array}{l}\text { Cervical and } \\
\text { thoracic spine tilt } \\
\text { angle }\left(^{\circ}\right)\end{array}$} & $E G(n=8)$ & $9.7 \pm 3.5$ & $3.9 \pm 3.6^{\#}$ & Time & $.000^{* * *}$ \\
\hline & & & & Group & .223 \\
\hline & $C G(n=8)$ & $10.0 \pm 6.1$ & $10.0 \pm 6.2$ & Time $x$ Group & $.000^{* * *+}$ \\
\hline
\end{tabular}

Values are $M \pm S D, " p<.05, * * * p<.001$, significant main or interaction effects.

" $p<.05$, significant different between the time.

EG: Exercise group, CG: Control group.

Table 7. Central asymmetry changes with CEC program.

\begin{tabular}{|c|c|c|c|c|c|}
\hline & Group & Pre & Post & & $P$ \\
\hline \multirow{3}{*}{$\begin{array}{l}\text { Central asymmetry } \\
\text { (kg) }\end{array}$} & $E G(n=8)$ & $6.4 \pm 2.5$ & $1.9 \pm 1.0^{*}$ & Time & $.001^{* *}$ \\
\hline & & & & Group & $.029^{*}$ \\
\hline & $C G(n=8)$ & $6.6 \pm 2.6$ & $6.7 \pm 2.6$ & Time x Group & $.001^{* * *+*}$ \\
\hline \multirow{3}{*}{$\begin{array}{l}\text { Shoulder angle } \\
\left({ }^{\circ}\right)\end{array}$} & $E G(n=8)$ & $3.0 \pm 1.2$ & $2.9 \pm 1.2$ & Time & .114 \\
\hline & & & & Group & .887 \\
\hline & $C G(n=8)$ & $3.1 \pm 1.3$ & $3.1 \pm 1.2$ & Time $x$ Group & .210 \\
\hline
\end{tabular}

Values are $M \pm S D, " p<.05, ", p<.01$, significant main or interaction effects.

" $p<.05$, significant different between the time.

EG: Exercise group, CG: Control group.

Table 8. Genu varus and genu valgus changes with CEC program.

\begin{tabular}{|c|c|c|c|c|c|c|}
\hline & & Group & Pre & Post & & $P$ \\
\hline \multirow{6}{*}{ Genu varus } & \multirow{3}{*}{$\begin{array}{l}\text { Knee centroid } \\
\text { distance }(\mathrm{cm})\end{array}$} & $E G(n=8)$ & $11.9 \pm 0.6$ & $8.0 \pm 1.3^{\#}$ & Time & $.000^{* * * *}$ \\
\hline & & & & & Group & $.000^{* * * *}$ \\
\hline & & $C G(n=8)$ & $11.9 \pm 0.7$ & $11.9 \pm 0.7$ & Time x Group & $.000^{*+* *}$ \\
\hline & \multirow{3}{*}{$\begin{array}{l}\text { Angle of femur and } \\
\text { tibia } \\
\left({ }^{\circ}\right)\end{array}$} & $E G(n=8)$ & $4.9 \pm 0.9$ & $3.3 \pm 0.9$ & Time & $.002^{* *}$ \\
\hline & & & & & Group & .060 \\
\hline & & $C G(n=8)$ & $5.0 \pm 0.9$ & $4.9 \pm 1.0^{\#}$ & Time x Group & $.005^{* *}$ \\
\hline \multirow{6}{*}{ Genu valgus } & \multirow{3}{*}{$\begin{array}{l}\text { Knee centroid } \\
\text { distance }(\mathrm{cm})\end{array}$} & $E G(n=8)$ & $4.5 \pm 0.6$ & $6.4 \pm 1.0^{\#}$ & Time & $.006^{*}$ \\
\hline & & & & & Group & .109 \\
\hline & & $C G(n=8)$ & $4.4 \pm 0.6$ & $4.7 \pm 1.3$ & Time x Group & $.037^{*}$ \\
\hline & \multirow{3}{*}{$\begin{array}{l}\text { Angle of femur and } \\
\text { tibia } \\
\left({ }^{\circ}\right)\end{array}$} & $E G(n=8)$ & $5.6 \pm 1.2$ & $3.8 \pm 0.9^{\#}$ & Time & $.001^{* *}$ \\
\hline & & & & & Group & .141 \\
\hline & & $C G(n=8)$ & $5.6 \pm 1.5$ & $5.7 \pm 1.4$ & Time $x$ Group & $.001^{* *}$ \\
\hline
\end{tabular}

Values are $\mathrm{M} \pm \mathrm{SD}, " p<.05,{ }^{\prime \prime} p<.01,{ }^{\prime \prime \prime} p<.001$, significant main or interaction effects.

" $p<.05$, significant different between the time.

EG: Exercise group, CG: Control group. 
유의하게 낮아졌으며, 목뼈 기울기는 실험군 $9.7 \pm 3.5$ ${ }^{\circ}$ 에서 $3.9 \pm 3.6^{\circ}{ }^{\circ}$ 으로 통계적으로 유의하게 낮아졌다 $(\mathrm{p}<.05)$.

중심비대층의 체중분배균형의 결과 $\mathrm{CEC}$ 프로그램 실 험군 $6.4 \pm 2.5 \mathrm{~kg}$ 에서 $1.9 \pm 1.0 \mathrm{~kg}$ 으로 감소하였으며, 집단과 시기 간 상호작용이 나타났다 $(\mathrm{p}<.05)<$ Table $7>$.

내반슬의 무릎 중심간거리는 $\mathrm{CEC}$ 프로그램 실험군 에서 $11.9 \pm 0.6 \mathrm{~cm}$ 에서 $8.0 \pm 1.3 \mathrm{~cm}$ 로 감소하였으 며, 집단과 시기 간 통계적 유의한 상호작용이 나타났 다 $(\mathrm{p}<.05)$. 넙다리뼈와 정강이뼈의 기울기 결과 $\mathrm{CEC}$ 프로그램 실험군 $4.9 \pm 0.9{ }^{\circ}$ 에서 $3.3 \pm 0.9^{\circ}$ 로 감소 하였으며, 통제군 $5.0 \pm 0.9^{\circ}$ 에서 $4.9 \pm 1.0^{\circ}$ 로 나타 나 집단과 시기 간 통계적 유의한 상호작용이 나타났다 $(\mathrm{p}<.05)<\mathrm{Table} 8>$. 또한, 외반슬의 무릎 중심간거리 결 과 $\mathrm{CEC}$ 프로그램 실험군 $4.5 \pm 0.6 \mathrm{~cm}$ 에서 $6.4 \pm 1.8 \mathrm{~cm}$ 증가하였으며, 통제군에서 $4.4 \pm 0.6 \mathrm{~cm}$ 에서 $4.7 \pm 1.3$ $\mathrm{cm}$ 로 나타나 집단과 시기 간 통계적 유의한 상호작용이 나타났다 $(\mathrm{p}<.05)$. 넙다리뼈와 정강이뼈의 기울기 각도는 $\mathrm{CEC}$ 프로그램 실험군 $5.6 \pm 1.2^{\circ}$ 에서 $3.8 \pm 0.9^{\circ}$ 로 감소 하였으며, 통제군 $5.6 \pm 1.5^{\circ}$ 에서 $5.7 \pm 1.4^{\circ}$ 로 나타나 집단과 시기 간 통계적으로 유의한 상호작용이 나타났고 $(\mathrm{p}<.05)$, 무를 중심간거리와 넙다리뼈와 정강이뼈의 기 울기에서 시기 간 주효과가 나타났다( $\mathrm{p}<.05)<$ Table 8>.

\section{논의}

본 연구는 자세불균형 성인을 대상으로 12 주간 주 3 회, 30 분 간 비대면 동영상 기반 홈트레이닝 $\mathrm{CEC}$ 프 로그램을 실시하여 전방머리자세, 중심비대칭, 내반슬, 외반슬에 미치는 영향을 규명하였다. CEC 실험군은 각 자 집에서 동영상을 보고 따라하는 비대면 홈트레이닝 방법으로 세라케인, 짐볼, 폼롤러, 덤벨, 메디신볼, 트레 이닝용밴드, 벽면 등을 이용하여 $\mathrm{CEC}$ 프로그램을 실시 하였다. $\mathrm{CEC}$ 프로그램 실시는 비대면으로 진행되었으 며 전문가가 $\mathrm{CEC}$ 프로그램을 녹화하여 대상자에게 전 달하였으며, 동영상 기반 피드백은 운동을 수행한 성과 에 대한 시각적 피드백을 추가하였다[27]. 자가 모니터 링 동영상 기반 피드백의 목적은 올바른 신체움직임 여 부를 알기가 어려울 것임으로 판단되며 지도자로부터의 특정 운동에 대한 자체 모니터링은 잘못된 운동 실행을
확인할 수 있다[28]. 자가 모니터링은 스스로의 실행 성과를 검토하고 즉각적으로 보강된 피드백을 받을 수 있어 목표로 하는 행동의 변화와 강화 피드백의 조합을 만들 수 있다[28]. 이와 같은 피드백 방법은 자신이 옳 고 그름을 타인에게 평가받지 않고, 의존하지 않기 때문 에 지속적인 행동 변화를 할 수 있다고 사료된다[28].

12 주간, 주 3 회, 30 분씩의 비대면 동영상 기반 홈트 레이닝 $\mathrm{CEC}$ 프로그램의 실시 결과, 전방머리자세의 중심 간거리 $(5.1 \pm 1.1 \mathrm{~cm}$ 에서 $2.1 \pm 1.8 \mathrm{~cm})$ 와 목뼈의 기울기 $\left(9.7 \pm 3.5^{\circ}\right.$ 에서 $\left.3.9 \pm 3.6^{\circ}\right)$ 에서 $\mathrm{CEC}$ 프로그램 실험군 의 긍정적인 개선이 나타났다. 전방머리자세의 중심간 거리가 1 inch 증가할 때마다 목뼈의 부하가 $10 \mathrm{lb}$ 씩 증 가하고[29], 목뼈의 각도는 $15^{\circ}$ 일 때는 $27 \mathrm{lb}, 30$ 일 때는 $40 \mathrm{lb}, 45^{\circ}$ 일 때는, $49 \mathrm{lb}, 60$ 일 때 $60 \mathrm{lb}$ 로 증가 하여 각도가 증가함에 따라 부하가 증가한다[30]. 목뼈 의 기울기는 전방머리자세의 정도를 정량화 하기 위해 일반적으로 사용되며, 교정 운동이 자세 교정에 미치는 영향에 관하여 검증한 연구는 매우 제한적으로 이루어 졌다. 본 연구의 결과에서 $\mathrm{CEC}$ 프로그램 실험군의 각도 가 유의하게 개선되었다는 것은 전방머리자세가 개선되 었음을 의미하며, 목뼈 기울기의 개선은 목뼈에 가해지 는 부하의 감소를 의미한다. 이와 같이 전방머리자세의 개선 효과는 자세 근육의 기계적 부하를 감소시키고, 목 의 통증을 완화할 수 있다고 사료된다[31].

전방머리자세는 목뼈의 굴곡근과 등, 어깨뼈 견인기 의 약화, 가슴 근육 및 목뼈의 신전근 단축과 관련이 있 다[32]. 전방머리자세는 작용근과 길항근 사이에서 근 육 균형을 회복하여 교정한다[33]. 상지의 흔한 근육 불균형 중 하나인 전방머리자세는 스마트폰이나 테블 릿pc, 컴퓨터 등 장시간 사용을 많이 하는 생활패턴에 의한 자세 문제로 인하여 전방머리자세 불균형이 되었 다. 이러한 자세 문제는 만성 두통, 경추 굴곡 및 확장 근육의 내구성 감소와 함께 나쁜 호흡 패턴, 심호흡을 동반하는 통증을 야기한다[34]. 선행연구에서는 이러 한 기형 조건을 무시하고 교정 운동과 고강도의 스트레 칭 강화 운동을 결합하여 개별적 교정에 초점을 두었다 [35]. 그러나 그 결과는 교정만으로는 설명할 수 없기 때문에 보다 효과적인 방법으로 본 연구에서는 $\mathrm{CEC}$ 프 로그램을 실시하였다.

중심비대칭은 체형분배균형의 실험군에서 감소 $(6.4 \pm 2.5 \mathrm{~kg}$ 에서 $1.9 \pm 1.0 \mathrm{~kg}$ )가 나타난 반면 어깨기 
울기에서는 유의한 변화가 나타나지 않았다. cec 프로 그램 실험군의 평균체중은 $64.2 \pm 11.0 \mathrm{~kg}$ 으로 체중분 배균형의 정상범위는 체중의 $5 \%$ 인 $3.2 \mathrm{~kg}$ 에 해당되어 야 하지만 정상범위의 2 배에 해당하는 수준이었다. $\mathrm{CEC}$ 프로그램 실시 후 체중분배균형이 $1.9 \pm 1.0 \mathrm{~kg}$ 으로 감 소되어 체중의 $5 \%$ 이내에 해당하여 정상범위로 개선 되었다. 이는 $\mathrm{CEC}$ 프로그램의 실시가 자세 개선에 효과 적임을 의미한다.

교정운동은 골격근의 적절한 활성화를 통해 신체 부 위의 정렬을 이상적인 상태로 만들어 자세를 개선시키 는데 활용되어 왔다. 선행연구에 의하면 후부 어깨와 경 추 근육을 강화는 수영선수의 경추와 흉추의 척추각도와 어깨 각도의 감소를 보고하였고[7], 요추전만증 환자를 대상으로 12 주간의 교정운동을 실시한 결과 요추 자세 를 개선시키는데 효과적이라고 하였다[36].

중심비대칭은 등쪽 부위의 상부 등세모근과 어깨뼈 근육의 단축은 목 굴곡근과 중간 및 하부 등세모근의 약 화를 동반한다[28]. 이 중심비대칭 패턴은 특히, C4-C5 분절, 등세모근과 같은 수축 근의 약화가 견갑골의 외전 을 증가시킨다. 교정 운동의 일반적인 원칙에 의하면 약 해진 근육을 강화시킬때 생체 역학적 움직임이 개선된 어 비정상 부위가 정상범위의 자세로 교정 될 수 있다 [37]. 본 연구에서 적용한 $\mathrm{CEC}$ 프로그램의 구성은 대상 자가 근육강화의 중점을 두어 능동적이고 역동적인 방 식으로 수행 할 수 있도록 구성하였다. 다른 교정운동 과의 차이점은 억제 단계에 있으며, 반복적인 움직임으 로 손상된 부위를 보호하거나 약한 근육을 보완하기 위 해 근육의 억제 또는 이완에 중점을 두었다.

본 연구에서 내반슬은 실험군에서 무릎중심간거리가 $11.9 \pm 0.6 \mathrm{~cm}$ 에서 $8.0 \pm 1.3 \mathrm{~cm}$ 로 나타나 $32 \%$ 의 감소 가 나타나 선행연구 결과[38]와 유사하였다. 내반슬의 4 단계의 불균형 척도로 나뉘며 1 단계는 $2.5 \mathrm{~cm}$ 이하, 2 단계는 $2.5 \sim 5 \mathrm{~cm}$ 이하, 3 단계는 $5 \sim 7.5 \mathrm{~cm}$ 이하이 고, 4 단계는 $7.5 \mathrm{~cm}$ 이상으로 4 등급 중 2 등급에 해당하 는 대상자이다[39]. 선행연구에서는 스트레칭과 탄성 밴드 운동을 통한 교정운동 프로그램을 적용하였다. 그 결과 근력 강화와 근육 이완을 통해 하지 정렬에 효과적 이라고 보고 하였으며[40], 내반슬 하지 변형자를 대상 으로 12 주간 스트레칭 운동과 탄성밴드 운동을 적용한 결과 무릎 사이 간격의 유의한 감소를 보고하였다[41]. 이는 3 등급이상 수술이 필요한 사람에 게 자세 불균형의
개선을 가져올 수 있으며, 지속적인 $\mathrm{CEC}$ 프로그램 실시 를 통한 불균형의 척도를 완화시킬 수 있어 수술 전 트레 이닝의 효과로 중요한 의미를 갖는다고 사료된다[28].

외반슬에서 실험군의 무릎중심간거리와 넙다리뼈와 정강이뼈의 기울기에서 유의한 차이가 나타났다 $(\mathrm{p}<.05)$. 외반슬은 다리의 앞쪽을 포함하는 하지의 자세 왜곡으 로 말단부 및 근위부와 함께 다리에 통증을 유발하고, 족저근막 부분에 장애를 일으킨다[28]. 선행연구에서 외반슬이 있는 남성을 대상으로 9개월간 NASM의 교 정운동을 실시한 결과 외반슬 각도와 내측복사뼈 사이 의 거리, 경골 대퇴각이 감소하여 하지 부정렬의 개선이 나타났으며 [42], 외반슬과 관련한 트레이닝은 하지각, 발목간격, 종골각 변화에 효과적인것을 나타났다[43]. 따라서 불균형된 외반슬의 개선을 위한 운동은 정상범 위의 하지관절을 만들기 위한 방법으로 중요한 의미가 있다고 판단된다.

\section{결론}

본 연구는 소셜 네트워크와 인터넷 커뮤니티 공개모 집을 통하여 자세불균형을 가진 성인 64 명을 대상으로 12 주간의 비대면 동영상 기반 홈트레이닝 CEC프로그 램 실시가 전방머리자세, 중심비대칭, 내반슬 및 외반슬 에 미치는 효과를 검토하였다.

그 결과, 전방머리자세, 중심비대칭, 내반슬 및 외반 슬을 긍정적으로 개선시키는데 효과가 있음을 확인하 여 동영상 기반 홈트레이닝 $\mathrm{CEC}$ 프로그램은 적절한 관 절 운동학을 복원하여 최적화된 신경근 제어를 복원하 고 근육 긴장을 감소시켜 자세와 균형을 안정적인 상태 로 복원할 수 있다고 사료된다. 앞으로 자세측정 및 통 합적인 관리가 가능한 통합프로그램 개발로 자세측정과 운동방법과 함께 결과 피드백 리포트를 제공하는 통합 솔루션 프로그램의 연구가 요구된다.

\section{Acknowledgments}

이 논문은 김진의 박사학위 논문을 수정 보완하였 습니다.

\section{Conflicts of Interest}

The authors declare no conflict of interest. 


\section{References}

1. Kang J, Park RY, Lee SJ, Kim, Y. J., Yoon, S. R., Jung, K. I. The effect of the forward head posture on postural balance in long time computer based worker. Ann Rehabil Med. 2012; 36(1):98-104.

2. Mahmoud NF, Hassan KA, Abdelmajeed SF, Moustafa IM, Silva AG. The Relationship Between Forward Head Posture and Neck Pain: A Systematic Review and Meta-Analysis. Curr Rev Musculoskelet Med. 2019; 12(4):562-577.

3. Harrison DE, Harrison DD, Betz JJ, et al. Increasing the cervical lordosis with chiropractic biophysics seated combined extension-compression and transverse load cervical traction with cervical manipulation: nonrandomized clinical control trial. J Manipulative Physiol Ther. 2003: 26(3):139-151.

4. Kim YH, Khil JH. Effects of Exercise Training and Chiropractic on Grip Strength and Cervical Muscle Strength of Subjects with Forward Head Posture and Turtle Neck. J Korean Soc of Phys Med. 2017; 12(2):121127.

5. Park CB, Cho WS, Choi AY. Effects of Unicycle Exercise for 8 Weeks on the Turtle Neck Posture in University Students. Archive of Orthopedic and Sports Physical Therapy. 2017; 13(2):65-70.

6. Johnson J. Postural Correction: Hands-On Guide for Therapists, Human Kinetics. 2016; 5:20-21.

7. Lynch SS, Thigpen CA, Mihalik JP, Prentice WE, Padua D. The effects of an exercise intervention on forward head and rounded shoulder postures in elite swimmers. Br J of Sports Med. 2010; 44(5):376-381.

8. Kluemper M, Uhl T, Hazelrigg H. Effect of stretching and strengthening shoulder muscles on forward shoulder posture in competitive swimmers. J Sport Rehabil. 2006; 15(1):58-70.

9. Mongashti JY, Fatahi F, Ghanizadeh HN, Hosseinpour E. Effect of genu varum deformity on gluteus medius muscle activity and postural control during single-leg jump-landing. J Phys Treatments. 2017; 7(2):79-88.

10. Bakhtiaty AH, Fatemi E, Rezasoltani A. Genu varum deformity may increase postural sway and falling risk
(Persian). Koomesh. 2012; 13(3):330-337.

11. Bansal S, Katzman WB, Giangregorio LM. Exercise for improving age-related hyperkyphotic posture: a systematic review. Arch Phys Med Rehabil. 2014; 95(1):129-140.

12. Azadinia F, Ebrahimi-Takamjani I, Kamyab M, Asgari M, Parnianpour M. Immediate Effects of Lumbosacral Orthosis on Postural Stability in Patients with Low Back Pain: A Preliminary Study. Arch Bone Jt Surg. 2019; $7(4): 360-366$.

13. Clark M, Lucett S. NASM essentials of corrective exercise training. Lippincott Williams \& Wilkins. 2010.

14. Espejo-Antúnez L, López-Miñarro PA, Albornoz-Cabello M, Garrido-Ardila EM. Acute effect of electrical muscle elongation and static stretching in hamstring muscle extensibility. Sci Sports. 2016; 31:e1-e7.

15. Sahrmann S, Azevedo, DC, Van Dillen L. Diagnosis and treatment of movement system impairment syndromes. Braz J Phys Ther. 2017; 21(6):391-399.

16. Page P, Frank C, Lardner R. Assessment and treatment of muscle imbalance: The Janda approach. J Hum Kinet. 2010, p38-56.

17. Lewis ZH, Lyons EJ, Jarvis JM, Baillargeon J. Using an electronic activity monitor system as an intervention modality: a systematic review. BMC Public Health. 2015; 15: p585.

18. Jordan JL, Holden MA, Mason EE, Foster NE. Interventions to improve adherence to exercise for chronic musculoskeletal pain in adults. Cochrane Database of Systematic Reviews. 2010; https://doi. org/10.1002/14651858.CD005956.pub2. (Accessed January 20, 2020)

19. Maniar N, Bennett E, Hand S, Allan G. The effect of mobile phone screen size on video based learning. J software. 2008; 3(4):51-61.

20. Lee DH. The effects of Balance and Stretching Exercise on Forward Head Posture. Daegu University. 2011.

21. Kang SH, Lee WJ, Kim TY. Possible Effects of Applying Rehabilitation Program upon Bowlegged Undergraduates` COG(Center of Gravity) Oscillation and its Correction. Kor Soc Sport Leis Stud. 2009; 35(2):1061-1072. 
22. Chae YW. The measurement of forward head posture and pressure pain threshold in neck muscle. J Kor Phys Ther. 2002; 14(1):117-124.

23. Yoon JY. The measurement and correlation analysis of pre and postoperative changes in torso deformities using 3-Dimentional body scanner and Scoliosis Research Society outcome Questionnaire (SRS-22) in scoliosis patient. University of Ulsan College. 2015.

24. Park JK, Nam YJ. Development of Method using Scanner for the Measurements of Foot Shape. J Ergon Soc Korea. 2002; 11:275-278.

25. Seok SH. The Effect of Functional Exercise for Growth and Development in Childhood and Adolescence Students with Genu Valgum. Kookmin University. 2013.

26. Bell DR, Vesci BJ, DiStefano LJ, Guskiewicz KM, Hirth CJ, Padua DA. Muscle activity and flexibility in individuals with medial knee displacement during the overhead squat. Athl Train Sports Health Care, 2012; 4(3):117125.

27. Kelley H, Miltenberger RG. Using video feedback to improve horseback-riding skills. J Appl Behav Anal. 2016; 49(1):138-147.

28. Kim J. Effects of Non-contact corrective exercise continuum for 12 weeks on postural imbalance in male and female adults. Kyunghee University. 2021.

29. Kapandji IA. The Physiology of the Joints- The Vertebral Column, Pelvic Girdle and Head Vol 3. 6th Ed. London: Churchill Livingstone. 2008.

30. Hansraj KK. "Assessment of stresses in the cervical spine caused by posture and position of the head." SURGICAL TECHNOLOGY INTERNATIONAL XXV. 2014; 25:277-279.

31. Lee S., Lee Y., Chung Y. Effect of changes in head postures during use of laptops on muscle activity of the neck and trunk. Phys Ther Rehabil Sci. 2017; 6(1):33-38.

32. Darling DW, Kraus S, Glasheen Wray MB. Relationship of head posture and the rest position of the mandible. J Prosthet Dent. 1984; 52(1):111-115.

33. Ruivo RM, Carita AI, Pezarat Correia P. The effects of training and detraining after an 8 month resistance and stretching training program on forward head and protracted shoulder postures in adolescents:
Randomised controlled study. Man Ther. 2016; 21:7682.

34. Kim MS, Cha YJ, Choi JD. Correlation between forward head posture, respiratory functions, and respiratory acCECsory muscles in young adults. J Back Musculoskelet Rehabil. 2017; 30(4):711-715.

35. Bae WS, Lee HO, Shin JW, Lee KC. The effect of middle and lower trapezius strength exercises and levator scapulae and upper trapezius stretching exercises in upper crossed syndrome. J Phys Ther Sci. 2016; 28(5):1636-1639.

36. Scannell JP, McGill SM. Lumbar posture-should it, and can it, be modified? A study of passive tissue stiffness and lumbar position during activities of daily living. Phys Tehr. 2003; 83(10):907-917.

37. Roshani S, Mahdavinejad R, Ghanizadeh N. The Effect of a NASM-Based Training Protocol on Upper Cross Syndrome in Paraplegia Spinal cord Injury Patients. J Ilam Univ Med Sci. 2018; 25(6): 73-85.

38. Yoo BG, Kim EH. The effects of the correction exercise program combined with stretching and elastic band exercise on femoral intercondylar distance, Q-angle, plantar pressure in undergraduate with genu varum. Kor Acad Ind Coop Soc. 2015; 16(3): 2064-2072.

39. Moon MS, Kim I, Kim BK. Treatment of bowleg-clinical observation of 18 cases-. J Korean Orthop Assoc. 1976; 11(3):353-362.

40. Han SK. The immediately effect of narrow squats on the knee joint biomechanics during a gait and distance between the knees of person with genu-varum. Hanseo University. 2017.

41. Han SM, Lee KK, Ha S, Sohn JH. “The effects of correction exercise on hip joint angle, Q-angle, and the distance between knees of genu varum patients". A J Kinesiol. 2011; 13(1):83-90.

42. Yoo HS. The effects of exercise program on body composition, pain, and correction of genu valgus with obesity. Seoul National University. 2017.

43. Shin YG. (The)effect of functional training for 24 weeks on knee joint structure and ankle spacing of young people during angular deformity growth period. Kookmin University. 2017. 